\title{
Isolation and Characterization of Probiotics Bacteria from Curd, Pickle and Fermented Rice and Screening of Antimicrobial Activity

\author{
Acharya Prangya Paramita ${ }^{1}$, Sahu Ajay Kumar ${ }^{*}$, Kar Barsha Rani ${ }^{3}$, Soni Abhisek ${ }^{2}$, Kumari \\ Shweta ${ }^{2}$, B Kiran kumar 4
}

${ }^{1}$ Dept of Biotechnology, Sambalpur University, Odisha, India

${ }^{2}$ Dept of Microbiology, Bangalore University, Bangalore, India

${ }^{3}$ Dept of Biotechnology, AMIT College, Bhubaneswar, India

4Dept. of Biotechnology, REVA University, Bangalore, India

\begin{abstract}
A B S T R A C T
The live supplement of microorganisms though the dietary product is known as the probiotics. These are some special kind of bacteria they are healthy for the host organisms. These bacteria commonly found in food and dietary product. In our study, Probiotics were isolated from fermented rice, curd and pickle. Total isolated strains were studied for their characterization, and also strains were studied antibacterial also their antibiotic susceptibility quality. The antibiotic resistance of poten tial strain was studied using Vancomycin, gentamycin, chloromphenicol, ciprofloxacin and cefataximide. PB1, PB3 shows the good resistance activity to the antibiotics. The curd produced by those strains has good quality and quantity of nutrients. Specially this study is for isolating, identifying, and characterizing the Probiotics .Isolated strains were identified by Gram staining, catalase assay, and 3 molecular identification methods; namely, (GTG) 5-PCR fingerprinting, This experiments shows the better anti-pathogen activity, and acceptable antibiotic susceptibility; it implies we can use these Probiotics in different purpose in food industry for modern food synthesis, for antimicrobial susceptibility test we are taking amplicin, karamycin, tetracycline, tripsin by using of the antibiotics concluded that various inhibition zones of given sample of probiotics.
\end{abstract}

Keywords- Probiotics, antimicrobial activity, curd, fermented rice, pickle, biochemical characterization

A R T I C L E I N F O: Received 30 Jan 2019; Review Completed 25 March 2019; Accepted 2 March 2019; Available online 15 April 2019

Cite this article as:

Prangya Paramita Acharya, Ajay Kumar Sahu*, Barsha Rani Kar, Priyanka patil, Kirankumar B, Isolation and characterization of Probiotics bacteria from curd, pickle and fermented rice and screening of antimicrobial activity, Asian Journal of Pharmaceutical Research and Development. 2019; 7(2):23-29, DOI:http://dx.doi.org/10.22270/aiprd.v7i2.481

*Address for Correspondence:

Ajay Kumar Sahu ${ }^{*}$ Dept. of Microbiology, Bangalore University, Kalayannagr, Banswadi, chelikere Ring Road, Bangalore, India

\section{INTRODUCTION}

I $\mathrm{n}$ India the traditional foods having some health benefits like rice which is the staple food of India have some beneficial health nutrients and also some beneficial microorganism after fermentation ${ }^{1}$. The dairy products are rich with ample amount of health-enhancing factor such as enriched nutrients. Most traditional Indian food pickle is the best source of some beneficial microorganisms as the source of probiotics. Probiotics are microorganism's active factors,

Which plays the main beneficial role on the host health ${ }^{2}$ .Probiotics have many benefits like it helps in absorption of nutrients, have antitoxin activity and antibiotics activity which significantly affect human body to maintain total physiology and metabolism ${ }^{1}$.
Most of Probiotics are isolated from safe sources, such as fermented dairy products, fermented rice and the food products. Most of the probiotic bacteria are from LAB (lattice acid bacteria) so these bacteria could not be identified and differentiated by traditional biochemical methods, so we need advanced type of biochemical method of characterization of this bacteria for clear results. In human body the Probiotics plays the main role in GI tract for proper absorption of food especially the protein ${ }^{3,4}$. The name Probiotics means uncountable bacteria .This bacteria have very long term growth it helps to increase and balance and reestablish the microbial population structure, with specific target Probiotics product affects the human alimentary tract as well as it reduce the risk of healing of human disease already known. Consumption of probiotic cells through food products is actually the most popular approach. In regular 
basis the consumption of Probiotics is very much necessary but it must be in proper fermentation level. They have many multipurpose capacities because they have very long time survival. Probiotic bacteria can sustain in very harsh environment they can adapt themselves in every pattern that's why they can easily survive in GI tracts and easily viable in it. As Probiotics have very much good effect in host body, it can be taken normally in the form of Probiotics capsule, syrup and food. It needs to stable itself in GIT at least cell counts become $106 \mathrm{CFU}$ g-1. The main source of Probiotics is from dietary products. As they are countless bacteria as compare to other microorganisms, it can be used in specific medical advantage ${ }^{4,5}$.

Probiotics are defined as a live microorganism which is adequate amount confer health benefits to the host, a live microbial fed supplement that beneficially affect the host animal by improving its intestinal microbial balance, Probiotics are generally used to improve the health of both animal and human through the modulation of the intestinal micro biota ${ }^{5}$. Several well characterized strains of lactobacillus and Bifid bacteria are available for human use to reduce the risk of gastrointestinal infection or treat such infection ${ }^{8}$. The primary clinical interest in the application of Probiotics has been used in prevention of and treatment of gastrointestinal infection and disease therefore the modulation of an unbalanced indigenous micro biota from the rational Probiotics therapy ${ }^{3,7}$.
Probiotics are microorganism that active factors, which show the beneficially impacts on the host health, Probiotics significantly affect the bioavailability of nutrient in the human body by facilitating the absorption of magnesium and calcium from milk proteins, lactobacillus and enterococcus species are common lactic acid bacteria gram positive and non toxic bacteria, which is usually consumed as probiotics 9 .

Probiotics bacteria under similar condition thus, these bacteria could not be identified and differentiated by traditionally phenotyping and biochemical methods. Such as sugar fermentation at genus levels as these techniques do not provide clear classification of result rapidly ${ }^{5}$. It is most importance that the Probiotics strains survive the sites where it is presumed to be active for maximum activity that strains should be able to proliferate and colonize at this specifics location, the Probiotics microorganism should be of human origin and must be able to survive and grow in the in vivo condition ${ }^{8,9}$.

And it must be able to tolerate low $\mathrm{Ph}$ and high concentration of both conjugated and de conjugated bile acids, Probiotics used should also be technologically compatible with the food manufacturing process and bacteria should be maintain the characterize sensory attributes of food production ${ }^{12}$.

\section{Benefits of Probiotics}

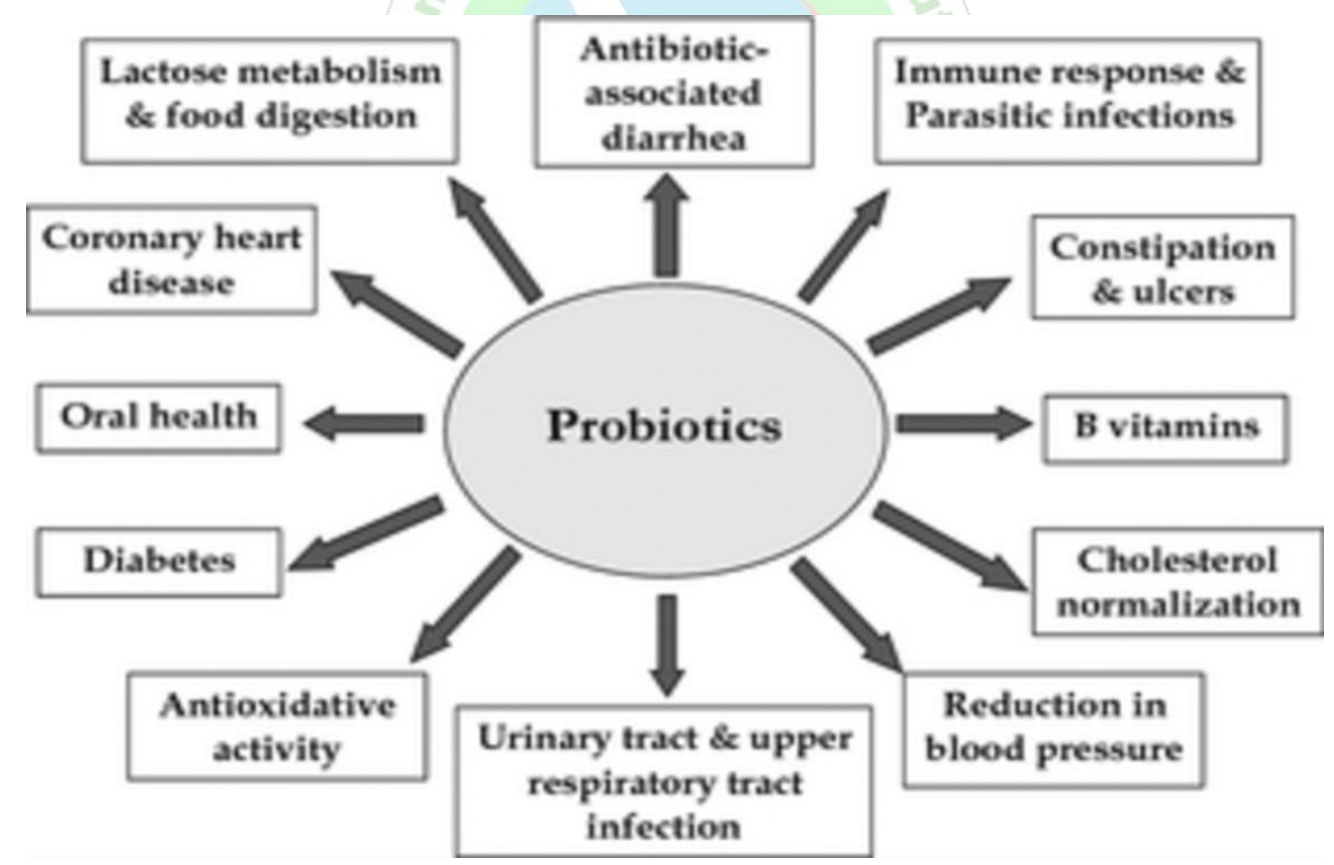

It is now an essential fact that the indigenous microbial communities is host Specific, location specific, very complex in composition and has been beneficially properties to host.

\section{Probiotics Health benefits and its mechanism}

- Resistance to enteric pathogens - Antagonism activity adjuvant effect increasing antibody production systemic immune effect.

- Aid in lactose digestion- Bacterial lactase acts on lactose in the small intestine.
- Small bowel bacterial overgrowth- lactobacilli influence the activity of overgrowth flora, decreasing toxic metabolic production.

- Immune system modulation- strengthening of nonspecific and antigen specific defense against infection and tumors adjuvant effect in the immune response.

- Anti colon cancer effect- Anti mutagenic activity detoxification of carcinogenic metabolites alternation in pro cancerous enzyme activity ${ }^{13}$. 


\section{Antimicrobial properties}

The intestinal microbial community is a complex ecosystem and introducing new organism into this highly competitive environment is difficult, thus microorganism can produce a product that inhibits the growth of existing organism have a characteristics advantage. The ability of Probiotics to establish in GI tracts is enhanced by their ability to eliminate competitors ${ }^{15}$.

Table 1: Probiotics bacteria

\begin{tabular}{|l|l|}
\hline \multicolumn{1}{|c|}{ Probiotics } & \multicolumn{1}{c|}{ Compound } \\
\hline Lactobacillus GG & Wide spectrum antibiotic \\
\hline L. acidophilus & Acidolin, Acidophilin \\
\hline L. bulgaricus & Bulgarican \\
\hline L. plantarum & Lactolin \\
\hline L. brevis & Lactobacillin \\
\hline L.reuteri & Reuterin \\
\hline L. sake L45 & Lactocin $S$ \\
\hline L. johnsonii & Lactocin $F$ \\
\hline L.helveticus & Helveticin \\
\hline L. cremoris & Diplococin \\
\hline
\end{tabular}

\section{Anti carcinogenic properties}

Probiotics suggest that diet and antibiotics can lower generation of carcinogenic in colon and reduce chemically induced tumors, these effect appear induced to be mediated through the intestinal microbial communities. A possible mechanism for these anticancer effects relies on inhibiting intestinal bacterial enzymes that convert procarcinogenes to more proximal carcinogens ${ }^{14}$.

Probiotics have also been found by several researchers to decrease fecal concentration of enzyme and secondary bile salt and reduce the absorption of harmful mutagens that may contribute to colon carcinogen.

\section{Probiotics in Diabetes and Obesity}

The role of gut flora in the pathology of insulin resistance and obesity has been well documented, animal and human studied have been suggested that gut flora enhance the body weight gain and increase the insulin resistance and these phenotype are transmissible with gut flora during the implantation studies of gut micro flora ${ }^{1,5}$.

\section{Mechanism action of Probiotics}

Probiotics bacteria have multiple and diverse influence on the host. Different organism can influence luminal environment, epithelial and mucosal barrier function and the mucosal immune system, the numerous cell type affected by Probiotics involve epithelial cell, dendritic cell, monocytes, and microphages ${ }^{2.6}$.

\section{MATERIAL AND METHODS}

\section{Sample collection}

Curd, pickle and fermented rice sample were collected from various market and fermented rice sample were collected from home making, two sample curd and pickle were chosen from different area Bangalore and store $37^{\circ} \mathrm{c}$ in incubator.

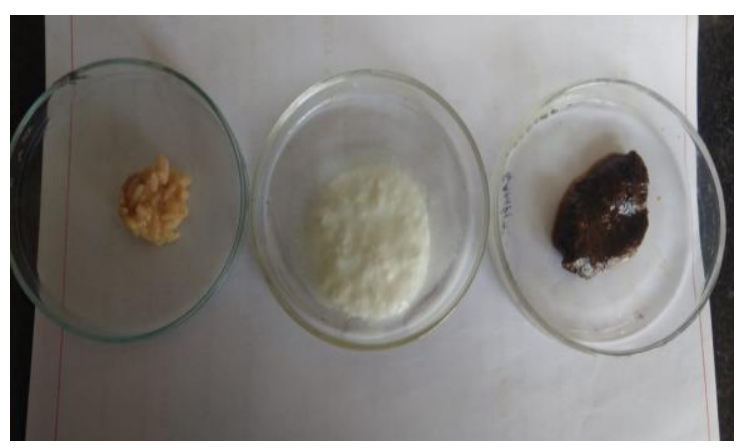

Figure 1: Serial Dilution

\section{Serial dilution}

To isolated antibiotics production microbes from sample, to isolate degrade microbes to remove contamination and to keep and clean the environments that are present in different seasons summer, winter, autumn.

\section{Methods}

- Serial dilution methods is one of the most old and usable methods which is use for the isolation of bacterial colony.

- In this method we take concern sample soil, water, milk, food make dilution in test tube.

- Inoculated this sample from the diluted test tubes in the prepared nutrient media plates by using pure plate methods and then incubated the cultured plates at $37^{\circ} \mathrm{c}$ for 24 hours.

- After 24 hours we absorb the cultured plates, the growth will appear on each plates.

A serial dilution is a the stepwise dilution of a substance in solution, the dilution factors at each step is constant, resulting in geometric progress of the concentration in log fashion, a tenfold serial dilution could be $1 \mathrm{M}$, $0.01,0.02,0.03,0.04,0.05,0.06,0.07,0.080,0.09,0.1 \mathrm{M}$ respectively.

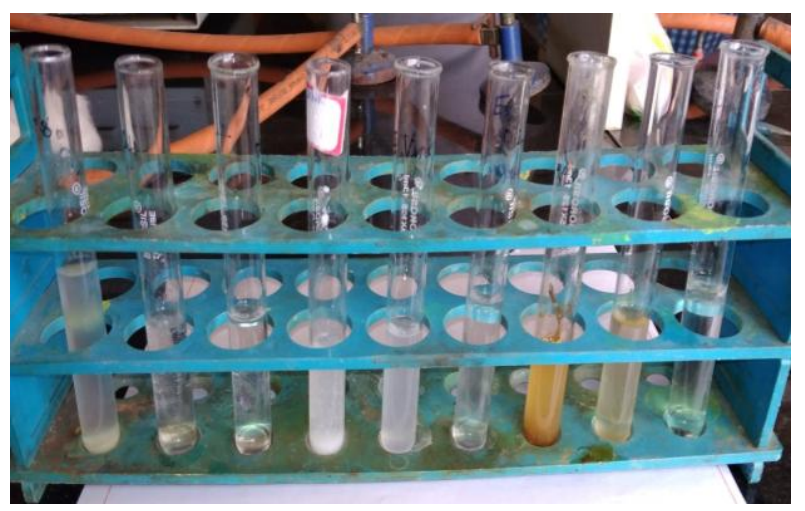

Figure 2: Serial Dilution

\section{Identification of Probiotics bacteria}

\section{Gram staining}

Prepare the smear in a clean slide make it heat fix, then add drops of crystal violet wait for $2 \mathrm{~min}$ then with distil water then add gram iodine wait for 1 min then clean with alcohol after that add counter strain saffrin and observe under microscope. 


\section{Biochemical characterization of bacteria}

\section{Indole test}

Peptone broth was prepared and sterilized at $121^{\circ} \mathrm{c}$ for 15 min and inoculated with test organism, incubated the medium at $37^{\circ} \mathrm{c}$ for 24 hours, Added $1 \mathrm{ml}$ of kovac reagent to tubes including control. Shook and observed the tubes for presence of rings.

\section{Methyl Red test}

Prepared MR-VP broth in two flasks, inoculate the broth with the test organism and incubated for 24 hours at $37^{\circ} \mathrm{c}$, after 24 hours of incubation transferred $5 \mathrm{ml}$ of broth into two test tubes. To the each broth culture added 5 drops MR indicator the tubes and shake them. Examine the colors of the each culture.

\section{Voges - proskauer test}

Prepared MR-VP broth in two flask, inoculate the broth with the test organism and incubated foe 24 hours, prepared BARRITT regent A and B. after 24 hours of incubation $0.5 \mathrm{ml}$ of reagent $\mathrm{A}$ and $0.2 \mathrm{ml}$ of reagent $\mathrm{B}$ was added to the broth and observe for color change.

\section{Citrate utilization test}

Prepared citrate agar slant and inoculated each of the test organism into appropriately labeled tubes by means of a loop, the slant was left UN inoculated that serve as control, incubated for 24 hours at $37^{\circ} \mathrm{c}$. After 24 hours all agar slant were examined for the presence of growth and coloration of the medium.

\section{Catalase test}

Transferred small quantity of culture from the plates on glass slide, add 1 drop of $3 \% \mathrm{H}_{2} \mathrm{O}_{2}$ observe bubbles formation.

\section{Oxidase test}

Taken oxidase disc in clean microscopic slide, pasted the culture on the oxidase disc and observed for color changes.

\section{Nitrate test}

Prepared nitrate broth and inoculated each of the test organisms into its appropriately labeled tubes means of a loop. The last slant was left un inoculated that serve as control, incubated all culture for 24 hours at $37^{\circ} \mathrm{c}$, after 24 hours add one dropper full of sulfanilic acid and one dropper full of $\alpha$ naphthylamine to each broth. Broth were examined for the change in coloration of the medium, a color change to red indicates a positive nitrate reduction test.

\section{Starch test}

Prepared starch agar and inoculated each of the test organism into its appropriately labeled tubes by means of a loop, the last plates was left un inoculated that serve as control, incubated all culture for 24 hours at $37^{\circ} \mathrm{c}$. after 24 hours all agar slants were examined for the presence of growth and zone formation on the medium, add iodine solution to see the zone formed more vividly.

\section{Gelatin test}

Prepared gelatin slant and inoculated each of the test organism into its appropriately labeled tubes by means of a loop. The slant was left un inoculated that serve as control, incubated all culture at the bacterium optimal growth temperature for up to 1 week and checked every day for gelatin liquefaction. Gelatin normally liquefies at $28^{\circ} \mathrm{c}$ and above, so to confirm that liquefaction was due to gelatinase activity. The tubes are immersed in an ice bath for 15 to $30 \mathrm{~min}$, Afterwards tubes are tilted to observe if gelatin has been hydrolyzed, hydrolyzed gelatin will results in liquid medium even after exposure to cold temperature (ICEBATH), and while the UN inoculated control medium will remain solid.

\section{Antimicrobial susceptibility}

The performance of antimicrobial susceptibility testing by clinical microbiology laboratory is important to confirm susceptibility to chosen empirical antimicrobial agents.

The disk diffusion susceptibility methods is simple and practical and has been well standardized, the test performed by applying bacterial inoculums of approximately $1-2 * 10^{8} \mathrm{cfu} / \mathrm{ml}$ to the surface of large Mueller Hinton Agar plates, up to 12 commercially prepared fixed concentration paper antibiotics disk are placed on the inoculated agar surface. Plates are incubated for $16-24$ hours at $37^{\circ} \mathrm{c}$ prior to determination of results; the zones of growth inhibition around each of the antibiotics are measured to the nearest millimeter. The diameter of the zones is related to the susceptibility of the isolate and to the diffusion rate of the drug through agar medium.

\section{RESULTS AND DISCUSSIONS}

Table 2: Biochemical Test

\begin{tabular}{|l|l|c|c|}
\hline Biochemical test & Fermented Rice & Pickle & Curd \\
\hline Indole & + & + & -- \\
\hline Methyl Red & -- & -- & + \\
\hline Voges- Proskauer & + & + & -- \\
\hline Citrate utilization & -- & -- & + \\
\hline Catalase & + & + & + \\
\hline Oxidase & -- & -- & + \\
\hline Nitrate & + & + & -- \\
\hline Starch & -- & + & + \\
\hline Gelatine & + & -- & + \\
\hline Gram staining & -- & + & + \\
\hline
\end{tabular}




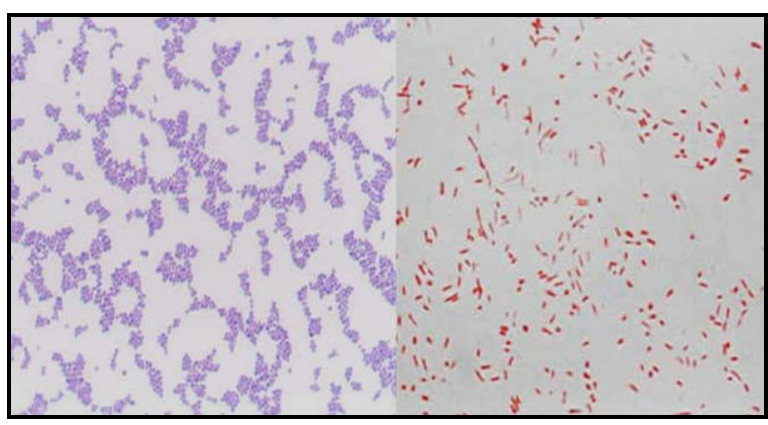

Figure 3: Gram Staining

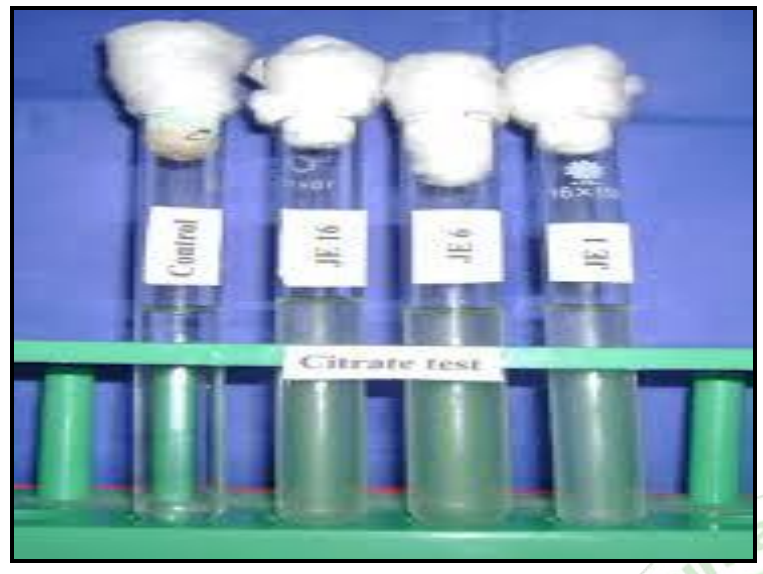

Figure 5: Citrate test

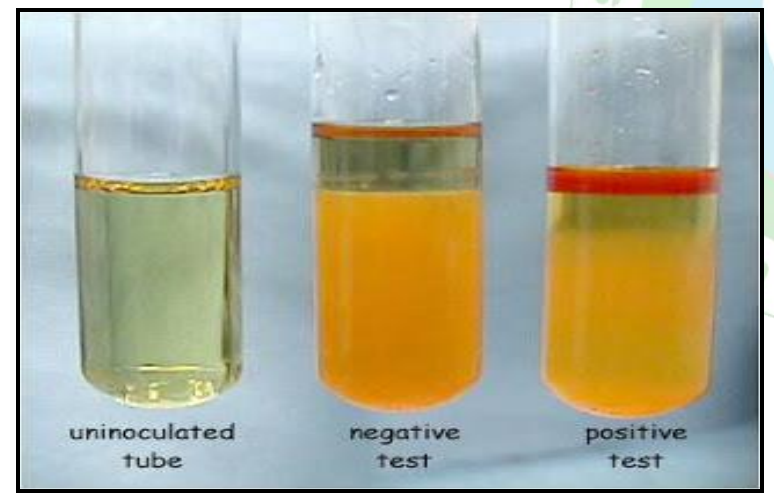

Figure 7: VP Test

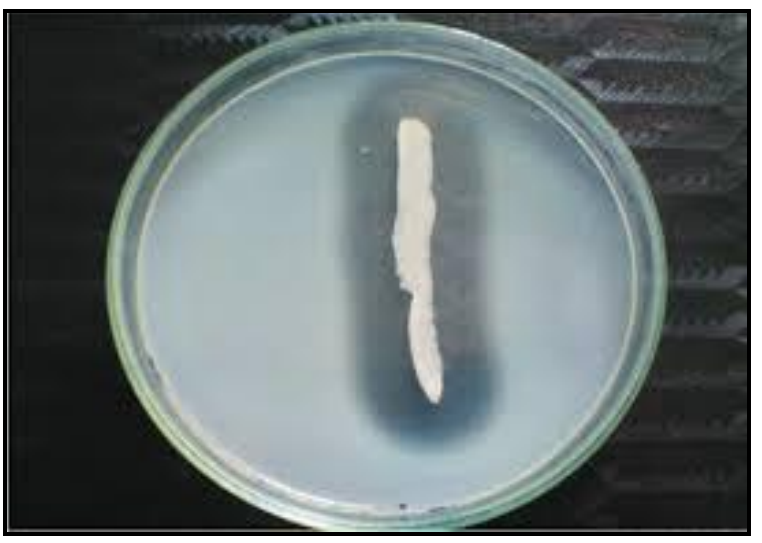

Figure 9: Starch Negetive

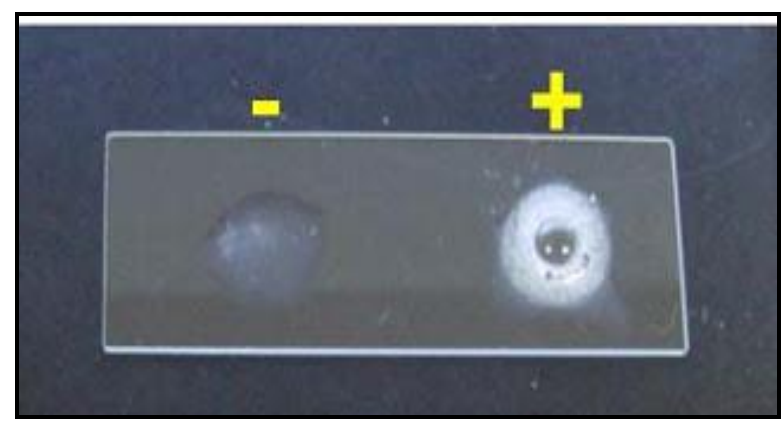

Figure 4: Catalase Test

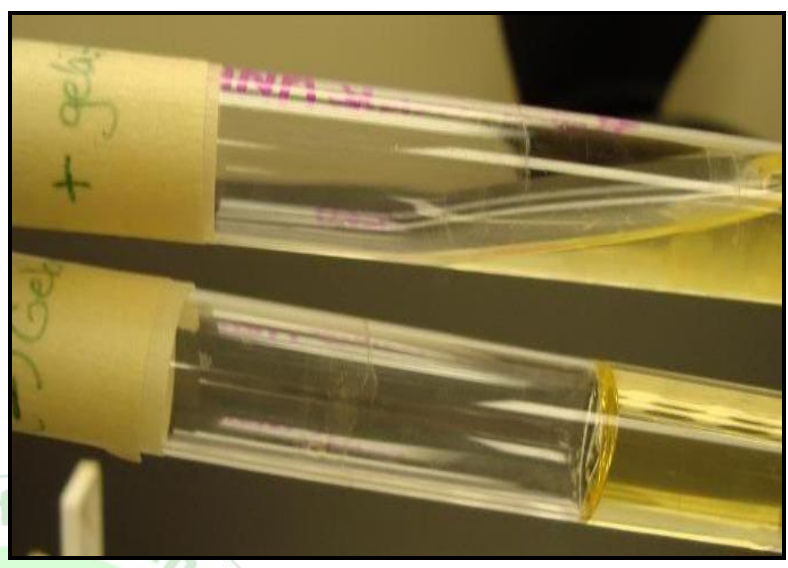

Figure 6: Gelatin test

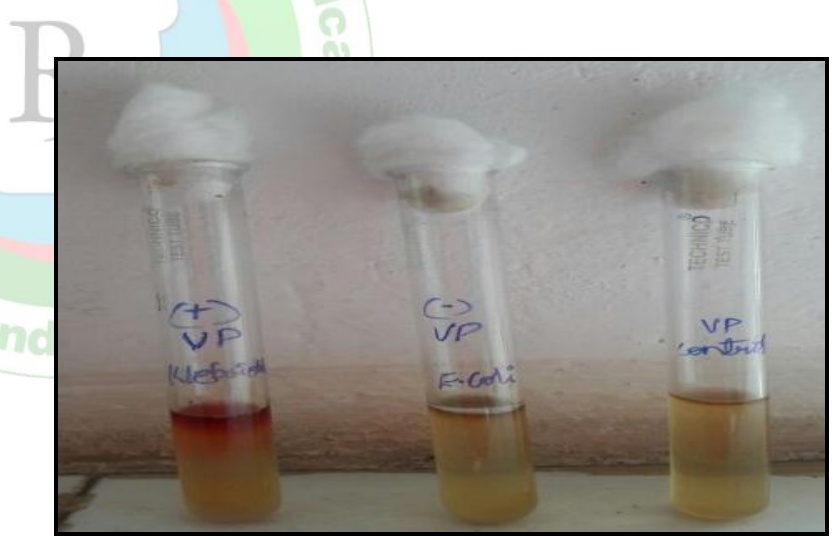

Figure 8: Methyl Red

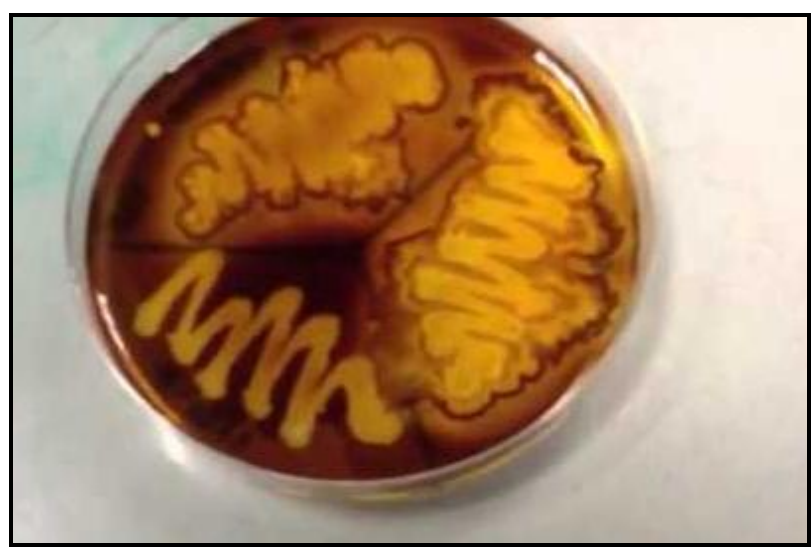

Figure 10: Starch Positive 


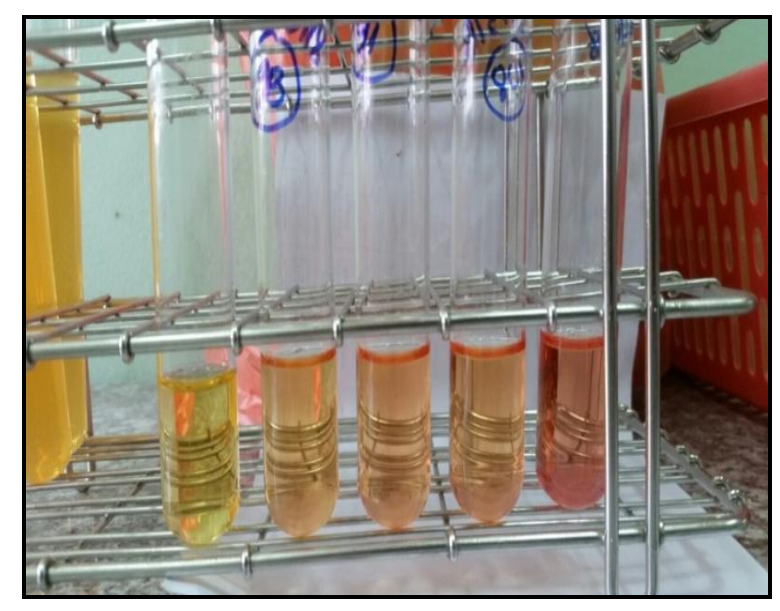

Figure 11: Urease Test

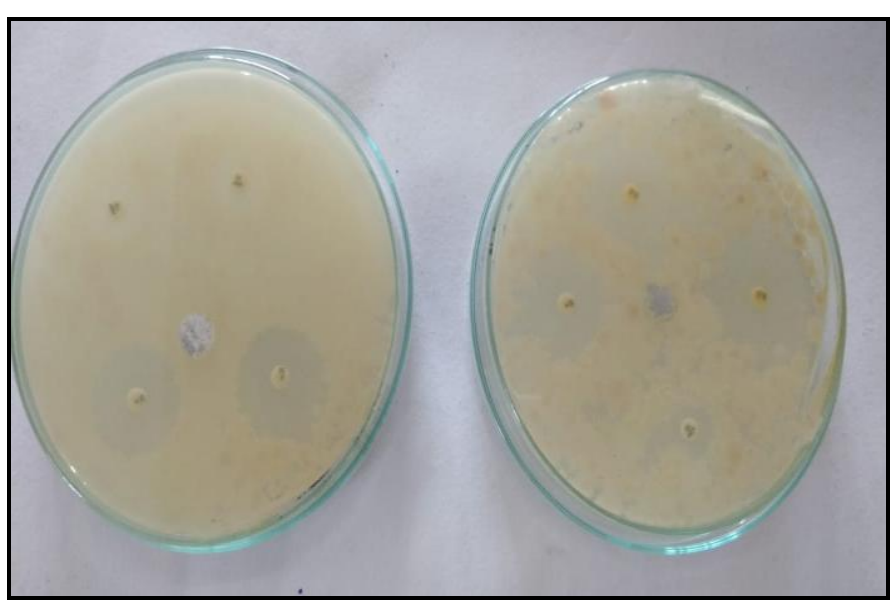

Figure 12: Antimicrobial susceptibility Test

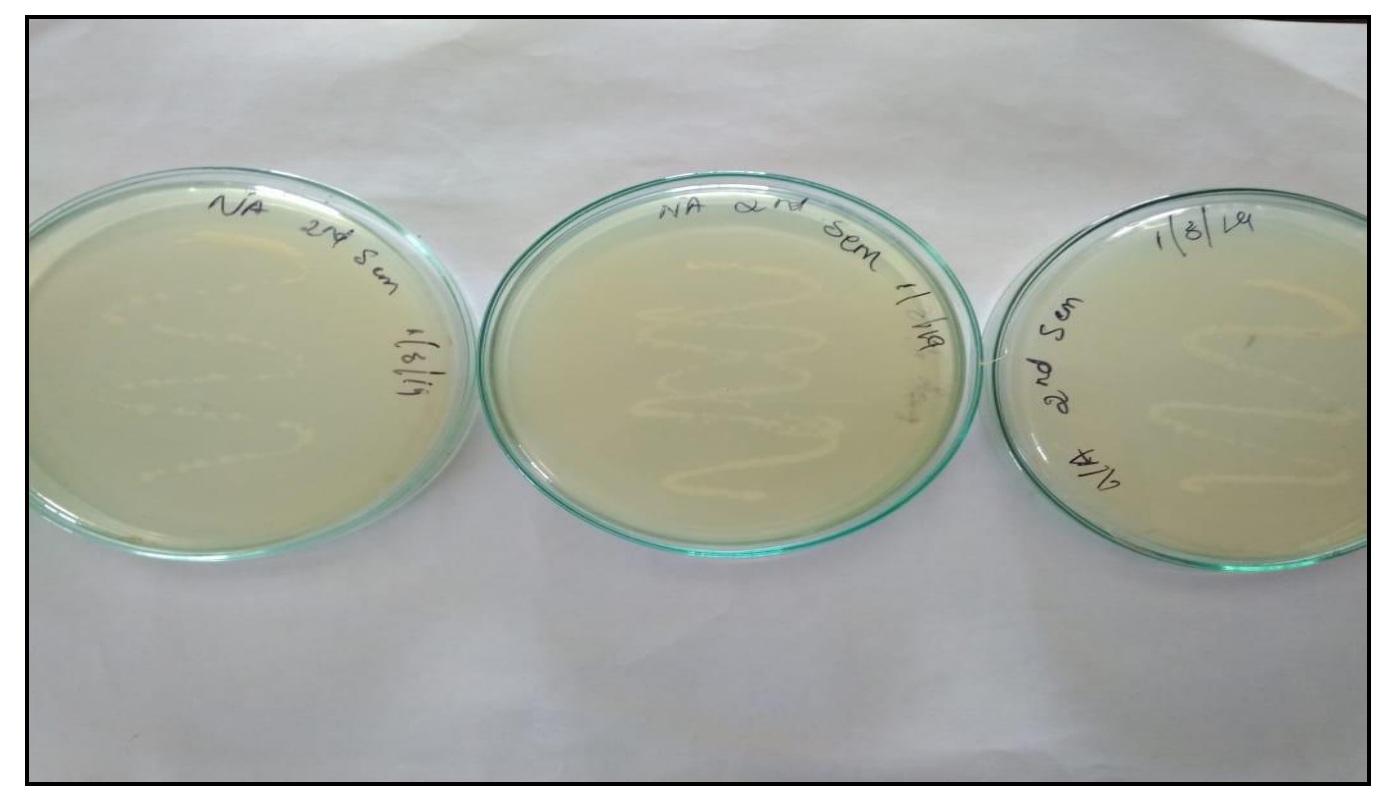

Figure 13: Screening of Probiotics Bacteria

\section{CONCLUSION}

Probiotic bacteria in fermented rice, curd, pickle could be a very good choice for value added products, the probiotic bacterial strain particularly lactobacillus casei and acidophilus with valuable count have the ability to produce good quality of curd, pickle and fermented rice and it Can be inhibit the pathogenic bacteria mass. It has been observed throughout the present research work, the curd produce by the identified strains showed good nutritional values, hence the study of characterization of probiotic bacteria and biochemical characterization is strongly supports the knowledge about the selection of inoculation for curd, fermented rice and pickle preparation especially on probiotic properties to promote the which bacteria of strain is present for which products and how its promote people health.
It would be possible to provide the basic information for the various production of probiotic feed products for various sources, it is also anticipated that deliverables of research work would be promote establishment of various society based environmentally suitable products industries by wider participation of vulnerable poor and destitute for society.

\section{REFERENCE}

1. Roblain D, Dauphin RD, Destain J, Diawara B, Thonart P assessment of physiological and biochemical characterization of lactic acid bacteria isolated from curd and pickle Afr. J. biotechnology. 2006; 5(8):629-634

2. Buckenhuskes HJ selection criteria for lactic acid bacteria to be used as starter culture for the various food commodities FEMS microbiology Rev. 1993; 12:253-272. 
3. Fuller R, Newport MJ 1987, the effect of diluted yogurt on the gut microbiology and growth of piglets, food microbiology 4:8385.

4. Fujisawa T, watabe J, Mitsuoka T lactobacillus aviaries spp, a new species isolated from the curd, system application microbiology. 1984; 5:414-420.

5. Fuller $\mathrm{R}$ Probiotic in man and animal: a review $\mathbf{J}$ application bacterial. 1989; 66:365-378.

6. Graciela FV, Maria PT, food microbiology protocols , Totowa new jersey, human press inc. chap.21, probiotic properties of lactobacillus 2001; 173-181.

7. MC farland LV, Beneficial microbes health or hazard, eur $\mathbf{J}$ gastroentrol hepatol 2005; 12:1069- 1071.

8. Mahantesh m patil, Ajay pal, T Anand and K V ramana, isolation characterization of lab from curd and cucumber, Indian journal of biotechnology, 2010; 9:166-172.

9. Reuter G, klein G and Goldberg m, identification of Probiotics culture feed sample, food research international 2004; 35 : 117124.

10. Parvathy seema nair Biochemical characterization of lab isolated from fish and prawn, journal of culture collection 2005; 44: 4852.

11. Sarvedra JM, Abi heena and moore A long term consumption of infant formula containing live Probiotics tolerance and safety, American journal clinical research 2008; 79: 261-67.

12. Keeney KM, Finlay BB, effect of antibiotic on human microbiota and subsequent disease, annu. Rev. Microbiology 2014; 68: 217 35

13. Croswell A, salzman NH the impact of antibiotic on microbial ecology to enteric salmonella infection immune. 2009; 77: 2741 53
14. Felis GE, Dellagilo f. taxonomy of lactobacillus and bifidobacteria. Current issue in intestinal microbiology 2007; 8: 44-61

15. Joint WHO working group report on drafting guideline for the evaluation of Probiotics in food Ontario: 2000

16. Saarela $\mathrm{M}$, Mongensen $\mathrm{G}$ fonden $\mathrm{R}$ probiotic safety functional and technological properties journal of biotechnology 2000: 84(3): 197- 215

17. Kosin B criteria for production of probiotic, food technology and biotechnology. 2006; 44(3): 371-379

18. Lahtinen SJ probiotic viability microbiology ecology in health and disease, 2012; 23: 10 -14

19. Salminen S, Benno y, Lee YK probiotic trends in food science and technology. 1999; 10(3): 107-110

20. Dysbiosis in infants is an important environmental factor of development origin of health and disease page: 43-54

21. Beneficial effects of Probiotics for infants and children with dysbiosis. Page 24-27

22. Bernardo petriz, metaproteomic approach to gut microbiota in health and disease pages: $58-78$

23. Probiotics and prebiotics, current research and trends, koen venema and paula do carmo. Pages; 34-45

24. Latic acid bacteria and bifidobacteria current progress in advance research, kenji sonomoto and atsushi yokota, pages 45-65

25. Venketeshwar and Leticia rao, Probiotics and prebiotics in human health and nutrition. 2007, pages: 34-67

26. Clinical infection disease and Probiotics benefits volume 45 February2007 pages 58-62

27. Yuan kun lee, baltasar mayo, basic fundamental of probiotic microorganism 14 july 2008, pages: 23-45. 